\title{
Review
}

\section{Body Fluid pH Balance in Metabolic Health and Possible Benefits of Dietary Alkaline Foods}

\author{
Wataru Aoi ${ }^{1, *}$, Xiaobo Zou ${ }^{2}$, Jian Bo Xiao ${ }^{2,3}$, Yoshinori Marunaka ${ }^{2,4,5,6, *}$ \\ ${ }^{1}$ Laboratory of Nutrition Science, Graduate School of Life and Environmental Sciences, Kyoto Prefectural University, Kyoto 606-8522, Japan \\ ${ }^{2}$ International Research Center for Food Nutrition and Safety, College of Food and Biological Engineering, Jiangsu University, Zhenjiang 212013, China \\ ${ }^{3}$ Institute of Chinese Medical Sciences, University of Macau, Taipa, Macau, China \\ ${ }^{4}$ Research Institute for Clinical Physiology, Kyoto Industrial Health Association, Kyoto 604-8472, Japan \\ ${ }^{5}$ Research Center for Drug Discovery and Pharmaceutical Development Science, Research Organization of Science and Technology, \\ Ritsumeikan University, Kusatsu 525-8577, Japan \\ ${ }^{6}$ Department of Molecular Cell Physiology, Graduate School of Medical Science, Kyoto Prefectural University of Medicine, Kyoto 602-8566, Japan
}

\section{ARTICLE INFO}

Article History

Received 04 June 2019

Accepted 18 September 2019

Keywords

$\mathrm{pH}$

interstitial fluid

food

diabetes

insulin resistance

\begin{abstract}
Living cells have several mechanisms to avoid acidic conditions created by excess protons. The protons are extruded to the extracellular space via the plasma membrane by various types of transporters such as the $\mathrm{Na}^{+} / \mathrm{H}^{+}$exchanger and monocarboxylate transporters, which hereby contribute to the exclusion of protons in the cells of metabolic tissues including the liver, skeletal muscle, and adipose tissue. Disturbances in the functioning of the transporters cause abnormal intracellular fluid $\mathrm{pH}$ of the cells and dysfunction of metabolic homeostasis, leading to the development of metabolic diseases and a decrease in physical fitness level. In addition to the intracellular fluid $\mathrm{pH}$ regulation, growing evidence shows that the fluid $\mathrm{pH}$ in the interstitial space around metabolic tissues is easily reduced due to weaker $\mathrm{pH}$ buffering capacity than that in the cytosol and blood circulation. Therefore, $\mathrm{pH}$ reduction in the interstitial fluid may cause the onset of metabolic dysfunction. In contrast, several dietary foods have direct and indirect benefits in maintaining the interstitial fluid $\mathrm{pH}$ to the normal range by improving buffering capacities, suppressing proton production, and activating proton transporters, which strengthen the effect of appropriate diet on metabolic health.
\end{abstract}

(C) 2019 International Association of Dietetic Nutrition and Safety. Publishing services by Atlantis Press International B.V. This is an open access article distributed under the CC BY-NC 4.0 license (http://creativecommons.org/licenses/by-nc/4.0/).

\section{INTRODUCTION}

Protons $\left(\mathrm{H}^{+}\right)$are produced from organic acids produced in living cells, and determine body fluid $\mathrm{pH}$ (the concentration of protons) [1-5]. Lactic acid (lactate $-/ \mathrm{H}^{+}$) is one of the major organic acid-producing protons and causes lower fluid $\mathrm{pH}$ [1]. Glycolytic metabolism of glucose and glycogen under anaerobic conditions generates lactic acid (lactate $/ \mathrm{H}^{+}$) in metabolic tissues such as skeletal muscles and adipose tissues. The $\mathrm{pKa}$ of lactic acid is $\sim 3.8$ at $37^{\circ} \mathrm{C}$ [6], therefore the generated lactic acid exists in ionized forms as lactate anion (lactate ${ }^{-}$) and protons at $\sim \mathrm{pH} 7.4$ (physiological conditions). In contrast to the utility of lactate as an energy substrate in aerobic metabolism system, as referred to in the concept "lactate shuttle," the dissociated protons are inducers of the acidic state [7,8]. Thus, the intracellular fluid $\mathrm{pH}$ is decreased under conditions of poor oxygen supply and excess glycolysis $[9,10]$. In addition, ketone bodies are other major sources of protons. $\beta$-Hydroxybutyric acid $\left(\beta\right.$-hydroxybutyrate $\left.{ }^{-} / \mathrm{H}^{+}\right)$is a major ketone body and a metabolite of fatty acid in the liver.

Corresponding authors. Email: waoi@kpu.ac.jp; marunaka@koto.kpu-m.ac.jp Peer review under responsibility of the International Association of Dietetic Nutrition and Safety
$\beta$-Hydroxybutyric acid exists in its ionized forms, $\beta$-hydroxybutyrate anion $\left(\beta\right.$-hydroxybutyrate $\left.{ }^{-}\right)$and protons, reducing the intracellular fluid $\mathrm{pH}[1,11,12]$.

The intracellular fluid $\mathrm{pH}$ of living cells is mostly maintained at alkaline levels by various systems (Figure 1). As typical examples, the bicarbonate-carbonate $\left(\mathrm{HCO}_{3}^{-}-\mathrm{CO}_{2}\right)$ system, protein-proton binding, and phosphoric acids $\left(\mathrm{H}_{3} \mathrm{PO}_{4}\right)$ act as proton-buffering systems. In addition, several membrane transporters have important roles in proton excretion from the cytosol to the extracellular space and contribute to the maintenance of alkaline $\mathrm{pH}$. For example, Monocarboxylate Transporters (MCTs) cotransport protons and monocarboxylate anions, such as lactate, pyruvate, betahydroxybutyrate, and acetoacetate, across the plasma (cellular) membrane $[9,10,13-17]$. In addition to these systems, the $\mathrm{Na}^{+} / \mathrm{H}^{+}$ Exchanger (NHE), $\mathrm{HCO}_{3}^{-}$-coupled transporters, and proton-coupled transporters also play key roles in the release of protons into the extracellular space $[9,10,18,19]$.

To maintain the intracellular $\mathrm{pH}$ in most living cells at alkaline levels as mentioned above, the acid produced in the intracellular space is extruded into the interstitial fluid (the extracellular fluid) $[1,9]$. Growing concepts suggest that the acidity of the interstitial fluid is one of the most serious pathogenesis causing various 


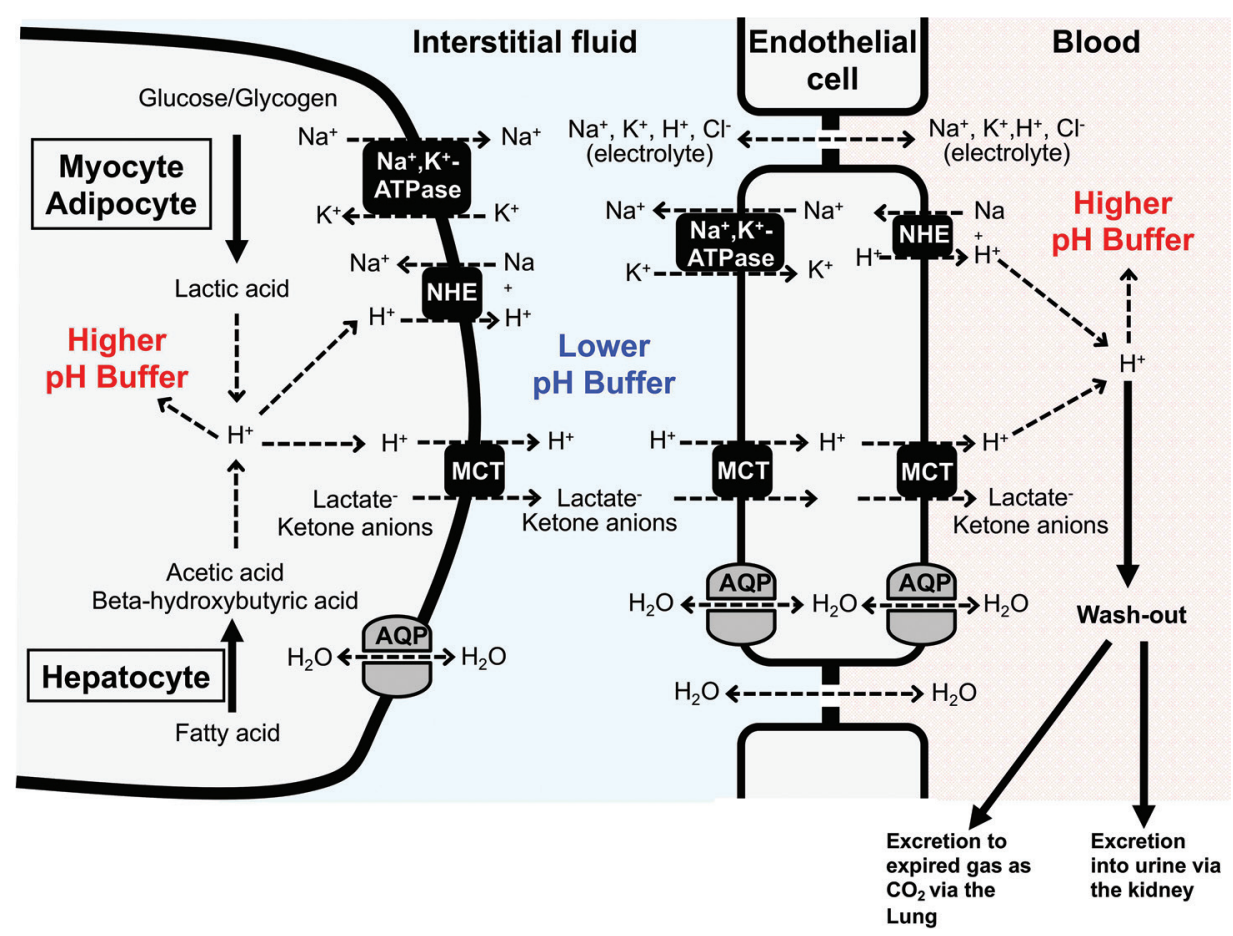

Figure 1 Cellular systems of $\mathrm{pH}$ homeostasis in metabolic organs. Elevation of glycolytic metabolism accelerates the production of lactic acid in both myocytes and adipocytes, whereas excess fatty acid metabolism in hepatocytes stimulates the production of ketone bodies, beta-hydroxybutyric and acetoacetic acids. The $\mathrm{pH}$-buffering systems, proton efflux across the plasma membrane, and proton excretion strictly maintain intra- and extra-cellular $\mathrm{pH}$. Monocarboxylate Transporter (MCT) and $\mathrm{Na}^{+} / \mathrm{H}^{+}$Exchanger (NHE) participate in proton extrusion from the cytosol to the extracellular space. Further, proton was exported to circulation through transport systems on endothelial cells. However, in contrast to intracellular fluid and blood, the interstitial fluid could easily turn acidic due to poor $\mathrm{pH}$-buffering factors such as proteins. AQP, aquaporin.

diseases including diabetes mellitus, tumor metastasis, and so on $[1,9]$ (see the detail in Section 4).

Dietary intervention is a crucial lifestyle change required to maintain the acid-base balance in the body fluid [1-3]. Several food factors have potential roles in improvement of the buffering capacity and proton transport systems in the cells of metabolic tissues; thus, these factors may be useful in preventing metabolic dysfunction $[1,2,4,5]$. This review focuses on the significance of regulation of intracellular and extracellular fluid $\mathrm{pH}$ and the possible benefits of dietary foods associated with the prevention of disease development and improving physical fitness level.

\section{BUFFERING AND EXCRETION OF PROTON IN PH REGULATION}

Homeostasis of intra-body environments is the most important matter for keeping the body healthy. Regulation of body fluid $\mathrm{pH}$ is one of the most important key factors for maintenance of homeostasis by controlling various cellular and molecular functions such as the enzymatic reactions. Homeostasis of body fluid $\mathrm{pH}$ is mediated by various $\mathrm{pH}$-buffering systems; for example, proton-binding proteins, such as albumin and hemoglobin $(\mathrm{Hb})$, and proton-extruding transporters from the intracellular space to the extracellular one ultimately outside the body. However, when extremely large amounts of acids are produced, $\mathrm{pH}$-buffering capacity is reduced, and/or proton-extruding transporting systems are impaired, the homeostasis of body fluid $\mathrm{pH}$ collapses, leading to health disorder.
Several buffering systems primarily contribute to the prevention of abnormal $\mathrm{pH}$ arising from excess proton production. A major buffering system is the bicarbonate-carbonate reaction in intracellular and extracellular fluids. The bicarbonate $\left(\mathrm{HCO}_{3}{ }^{-}\right)$reacts with proton and is protonated to $\mathrm{H}_{2} \mathrm{CO}_{3}$, and then establishes equilibrium with the dissolved $\mathrm{CO}_{2}$ and $\mathrm{H}_{2} \mathrm{O}$. The acid-base metabolism in the body is thus regulated by the following equilibrium equation: $\mathrm{CO}_{2}+\mathrm{H}_{2} \mathrm{O} \rightleftharpoons$ $\mathrm{H}_{2} \mathrm{CO}_{3} \rightleftharpoons \mathrm{H}^{+}+\mathrm{HCO}_{3}{ }^{-}(\mathrm{pKa}=6.10)$. Finally, the $\mathrm{CO}_{2}$ is exhaled or removed mainly via breathing gas from the lungs, which accounts for the removal of proton. Some part of proton is also excreted into urine. Another system that mediates proton buffering is the protein-proton binding. Proteins are composed of amino acids and their functional groups act as weak acids and bases to stabilize the $\mathrm{pH}$ within a normal physiological range in the living bodies. In addition, phosphoric acid acts as a buffering factor according to the following equation:

$$
\begin{aligned}
& \mathrm{H}_{3} \mathrm{PO}_{4} \rightleftharpoons \mathrm{H}^{+}+\mathrm{H}_{2} \mathrm{PO}_{4}^{-} \quad(\mathrm{pKa}=2.12), \\
& \mathrm{H}_{2} \mathrm{PO}_{4}^{-} \rightleftharpoons \mathrm{H}^{+}+\mathrm{HPO}_{4}^{2-} \quad(\mathrm{pKa}=7.21), \quad \text { and } \\
& \mathrm{HPO}_{4}^{2-} \rightleftharpoons \mathrm{H}^{+}+\mathrm{PO}_{4}^{3-} \quad(\mathrm{pKa}=12.67) .
\end{aligned}
$$

These intracellular buffering systems contribute to the maintenance of fluid $\mathrm{pH}$ within the physiological range and protection of the cellular events. The overall physiological range of the intracellular $\mathrm{pH}(\sim 7.03-7.46)$ is much wider compared with that of the arterial blood $\mathrm{pH}$ (7.35-7.45), as the physiological range of the intracellular $\mathrm{pH}$ is different among various types of cells [20]. Although the overall physiological range of the intracellular $\mathrm{pH}$ is very wide ( 7.03-7.46) among various types of cells, the intracellular $\mathrm{pH}$ of each cell is strictly fixed at its own value depending on its cell type 
with a variable range of $<0.1$ unit by the intracellular $\mathrm{pH}$-buffering system described above $[20,21]$.

Proton transport across the plasma membrane is also important for maintaining the intracellular $\mathrm{pH}$, particularly in the skeletal muscle, a major metabolic organ generating acids. In the contracting muscle, over $80 \%$ of the intracellular protons are transported from cytosol to extracellular space via the monocarboxylate transport system (MCTs), whereas the remaining protons are transported via the $\mathrm{NHE}, \mathrm{HCO}_{3}^{-}$-coupled transporters, and proton-coupled transporters $[22,23]$. After exercise the intracellular fluid $\mathrm{pH}$ shows delayed recovery to the basal condition in a case with the absence of proton transporters [24], suggesting that proton transporters play a key role in maintaining fluid $\mathrm{pH}$ homeostasis. Thus, the regulation of proton transporters is closely associated with the capacity for $\mathrm{pH}$ maintenance $[24,25]$. In the liver, other organic acids, such as ketone bodies (i.e., acetoacetic and $\beta$-hydroxybutyric acids), are produced with fatty acid metabolism. Therefore, the fluid $\mathrm{pH}$ condition of intra-hepatocytes is easily disturbed [26-28], and the intracellular fluid $\mathrm{pH}$ should be maintained by the $\mathrm{pH}$-buffering systems and proton efflux.

Monocarboxylate cotransporters (a part of the solute carrier 16 family) cotransport monocarboxylate anions with proton across the plasma membrane. Different transport kinetics and location in 10 of the total 14 isoforms are characterized in Table 1. MCT1MCT4 are mainly expressed in the cells of metabolic tissues such as skeletal muscle, adipose tissues, and the liver, and carry out the transport of lactate, pyruvate, and ketone bodies [14]. The direction of transport across the plasma membrane is dependent on the concentration gradient of protons and monocarboxylate [28-30]. When excess monocarboxylic acids are generated, MCTs play crucial roles in prevention against the acidic state. It has been known that the functional expression of MCT1 and MCT4 strongly affects lactate disposal in myocytes. MCT1 is highly expressed in the plasma membrane of slow twitch muscles [16,32,33]. In contrast, MCT4 is the predominant isoform found on the plasma membrane of fast twitch muscle, and transports lactate and proton from the cytosol to the extracellular space [31,33]. Another isoform MCT2 is mainly expressed on the plasma membrane of hepatocytes and exports ketone bodies to the extracellular fluid [34].

$\mathrm{Na}^{+} / \mathrm{H}^{+}$exchanger also acts as a major proton transporter that maintains the intracellular fluid $\mathrm{pH}$ homeostasis. It extrudes the intracellular proton by taking in the extracellular $\mathrm{Na}^{+}$using the $\mathrm{Na}^{+}$ chemical gradient between intra- and extra-cellular fluids $[18,35]$. NHE1-NHE5 of the total 10 isoforms are located on the plasma membrane of their specific tissues [35-37]. NHE1 is well known to act as a ubiquitous isoform and to contribute in the maintenance of $\mathrm{pH}$ homeostasis in metabolic organs.

\section{3. pH DISTURBANCE IN PHYSIOLOGICAL AND PATHOLOGICAL CONDITIONS}

The $\mathrm{pH}$ of arterial blood in mammals is strictly maintained within a range of 7.35-7.45 under physiological conditions. A decrease from the normal $\mathrm{pH}$ to $<7.35$ results in the condition of acidosis. During exercise, the elevated level of lactic acid production leads to the acidic state of the tissues and dysfunction of muscle contraction $[38,39]$. Although it depends on the intensity of exercise, strenuous contraction of the muscles can sometimes transiently reduce the $\mathrm{pH}$ of intramuscular fluid to $\sim 6.5$ that is associated with $>40 \mathrm{mM}$ lactate accumulation in the intramuscular space $[22,38,39]$. In diabetic pathological condition, the body fluids of patients often show a chronic acidic state, called ketoacidosis, caused by excess production of ketone bodies [40,41]. The utilization of lipids instead of glucose for energy supply is accelerated in the liver, skeletal muscles, and adipose tissues with insulin resistance. The extreme large utilization of lipids (lipolysis) results in elevation of circulating fatty acids, causing the generation of ketone bodies via fatty acid oxidation in the liver. This process leads to high production of protons, 'overloading protons', which causes the metabolic ketoacidosis frequently observed in diabetic patients. The acidic conditions diminish activity of enzymes contributing to glucose metabolisms, such as phosphofructokinase, progressing pathophysiological conditions [40-42] and physical fatigue [43,44].

Loss of function of MCTs has been reported to disturb the body fluid $\mathrm{pH}$ homeostasis. The transport activity and substrate specificity of the MCT are influenced by various point mutations of the MCT gene. The mutation of arginine 306 to threonine in domain 8 of MCT1 spontaneously occurring has lower transport activity compared with the wild type MCT1 [45]. The mutated MCT1 with much lower transport activity delays recovery from high blood lactate after exercise [46,47]. A defect in lactate efflux from muscles due to the mutation of MCT1 would cause severe chest pain

Table 1 Characteristics of monocarboxylate transporter family

\begin{tabular}{lll}
\hline Isoform/Name & Major location & Major substrate \\
\hline MCT1/SLC16A1 & Ubiquitous esp. erythrocyte, skeletal muscle (oxidative), heart, intestine & Lactate, pyruvate, butyrate, ketone bodies \\
MCT2/SLC16A7 & Testis, spleen, brain, liver, kidney, pancreas & Pyruvate, lactate, ketone bodies \\
MCT3/SLC16A8 & Retinal pigment epithelium, choroid plexus & Lactate \\
MCT4/SLC16A3 & Skeletal muscle (glycolytic), leukocyte, astrocytes, chondrocyte, intestine, lung & Lactate, pyruvate, ketone bodies \\
MCT5/SLC16A4 & Brain, muscle, liver, kidney, lung, placenta & Unknown \\
MCT6/SLC16A5 & Kidney, muscle, brain, pancreas, prostate, lung & Drugs (bumetanide, nateglinide, probenecid) \\
MCT7/SLC16A6 & Brain, pancreas, liver & Ketone bodies \\
MCT8/SLC16A2 & Liver, heart, brain, thymus, intestine, ovary, prostate, placenta, skeletal muscle & Thyroid hormones \\
MCT9/SLC16A9 & Endometrium, testis, ovary, breast, brain, retina & Carnitine \\
MCT10/SLC16A10 & Kidney, intestine, skeletal muscle, heart & Aromatic amino acids \\
MCT11/SLC16A11 & Skin, lung, pancreas, breast, ovary & Unknown \\
MCT 12/SLC16A12 & Kidney, lung, retina & Creatine \\
MCT 13/SLC16A13 & Bone marrow cells, breast & Unknown \\
MCT14/SLC16A14 & Heart, brain, ovary, breast, pancreas & Unknown \\
\hline
\end{tabular}


and muscle cramping after strenuous exercise. Furthermore, many differences in amino acids, not attributable to polymorphisms, are found in MCT1 obtained from muscle tissues in these subjects [46]. These findings suggest that mutations in MCT1 would be one of causes for physical fatigue and exercise performance. In contrast, the activity of lactate transport in muscle is also decreased by denervation and aging $[48,49]$. Dysfunction of MCT might be associated with metabolic disorder. The skeletal muscle of obese rats shows lower leveled expression of MCT1 and MCT4 than that in normal rats [50]. Notably, the study using heterogenous mct1expressed mice $\left(\mathrm{MCT1}^{+-}\right)$has shown a prevention in the development of diet-induced obesity and insulin resistance, suggesting that the MCT1 transporter can be a therapeutic target to prevent and treat obesity [51]. Further, this mutated mouse exhibited a higher acidic condition associated with lower carbonic anhydrase II contents [52], suggesting the important contribution of MCT1 in the acid-base balance of the body. In addition, the level of circulating lactate significantly shows a negative correlation to the degree of insulin sensitivity in humans [53,54], suggesting that insulin resistance would be caused by the lower lactic acid disposal caused by the reduction of MCT function.

\section{INTERSTITIAL FLUID pH AND DISEASE DEVELOPMENT}

Fluid $\mathrm{pH}$ in the interstitial space of metabolic tissues is easily reduced due to lower $\mathrm{pH}$-buffering capacity than cytosol and blood circulation (Figures 1 and 2). The production of lactic acid is accelerated by elevating glycolytic metabolism in both myocytes and adipocytes [1] (Figure 1). In hepatocytes, the production of ketone bodies, beta-hydroxybutyric and acetoacetic acids, is accelerated by excess fatty acid metabolism [11,55]. Intra- and extra-cellular $\mathrm{pH}$ is strictly maintained by $\mathrm{pH}$-buffering systems, proton efflux across the plasma membrane, and proton excretion [1] (Figure 1). Proton is transcellularly extruded from the cytosol to the extracellular space (the interstitial space) mainly by MCT and NHE (Figure 1). NHE, an electroneutral transporter, participates in $\mathrm{H}^{+}$extrusion using the much higher chemical potential (concentration) of $\mathrm{Na}^{+}$in the interstitial space than that in the intracellular space of myocyte, adipocyte, and hepatocyte even in the case of the higher $\mathrm{H}^{+}$chemical potential (higher $\mathrm{H}^{+}$concentration: lower $\mathrm{pH}$ ) in the interstitial space than that in the intracellular space of myocyte, adipocyte, and hepatocyte. This means that NHE has potential to actively extrude $\mathrm{H}^{+}$to the interstitial space from the intracellular space of myocyte, adipocyte, and hepatocyte (Figure 1) using the much higher chemical potential of $\mathrm{Na}^{+}$in the interstitial space than that in the intracellular space. On the other hand, unlike NHE, MCT (an electroneutral transporter) has little high chemical potential for $\mathrm{H}^{+}$ extrusion from the intracellular space of myocyte, adipocyte, and hepatocyte to the interstitial one. The extrusion of $\mathrm{H}^{+}$, lactate and ketone anions to the interstitial space from the intracellular space of myocyte, adipocyte, and hepatocyte is driven by the summation of the chemical potentials of these anions (Figure 1). This means that in case of higher concentration of lactate and ketone anions in interstitial space than that in the intracellular space of myocyte, adipocyte, and hepatocyte, MCT could not actively extrude $\mathrm{H}^{+}$to the interstitial space from the intracellular space of myocyte, adipocyte, and hepatocyte. In case the interstitial $\mathrm{pH}$ is lower than the intracellular $\mathrm{pH}$ of myocyte, adipocyte, and hepatocyte (the interstitial $\mathrm{H}^{+}$concentration $>$the intracellular $\mathrm{H}^{+}$concentration), lactate and ketone anions in the intracellular space of myocyte, adipocyte, and hepatocyte could not be actively extruded to the interstitial space. Therefore, to actively extrude lactate and ketone anions to the interstitial space from the intracellular space of myocyte, adipocyte, and hepatocyte, the interstitial $\mathrm{pH}$ should be kept higher than the intracellular $\mathrm{pH}$ of myocyte, adipocyte, and hepatocyte (the interstitial $\mathrm{H}^{+}$concentration $<$the intracellular $\mathrm{H}^{+}$concentration).

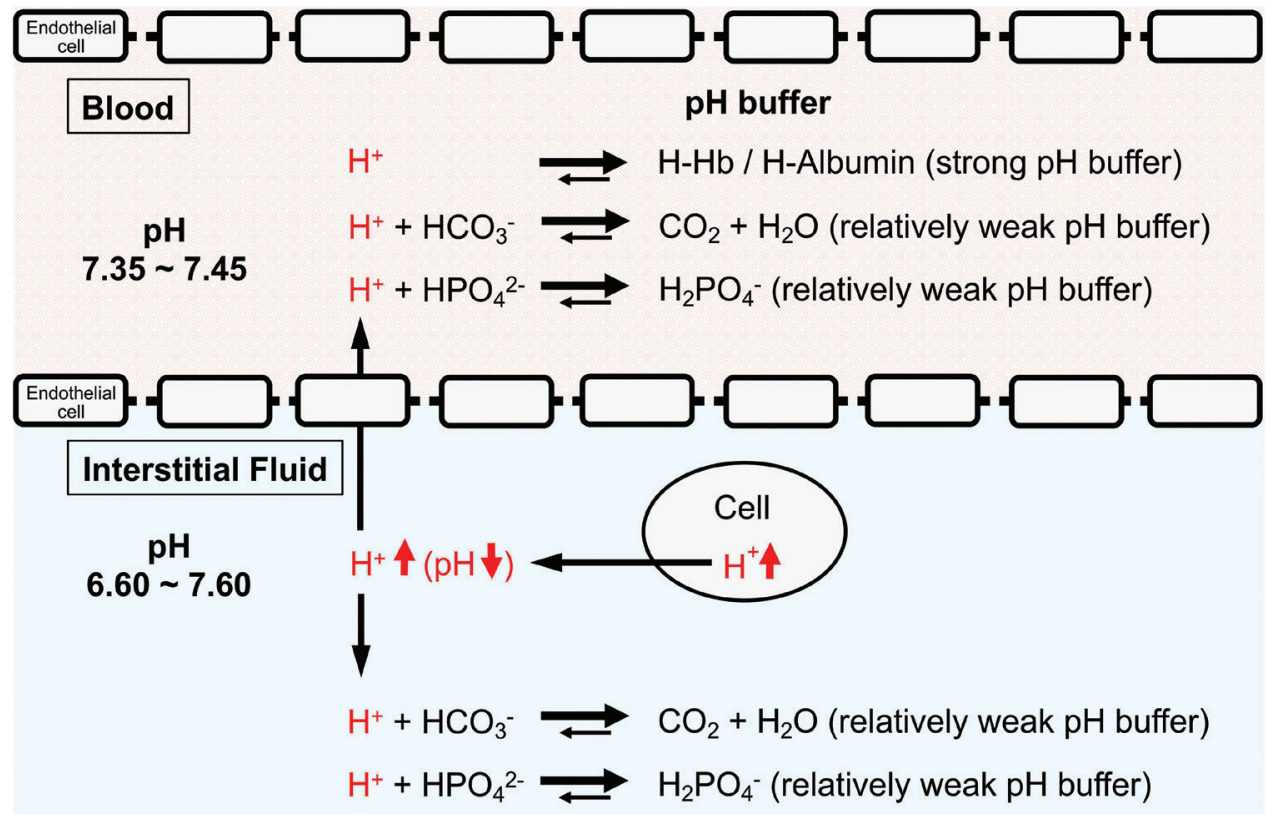

Figure 2 pH-buffering systems in blood and interstitial fluids. Blood has strong pH buffers such as hemoglobin (Hb) and albumin, whereas interstitial fluids have weak pH-buffering molecules such as bicarbonate and phosphate molecules. This means that even under mild but not severe metabolic disorder conditions the arterial blood $\mathrm{pH}$ is maintained constant within the normal range (7.35-7.45), whereas the interstitial fluid $\mathrm{pH}$ becomes lower than the normal level. Modified from Figure 1 in Marunaka [1]. 
The transport system of $\mathrm{H}^{+}$, lactate and ketone anions from the interstitial space to blood has an essential role in keeping the driving force for extrusion of $\mathrm{H}^{+}$, lactate and ketone anions via MCT from the intracellular space of myocyte, adipocyte, and hepatocyte (lowering the concentration of $\mathrm{H}^{+}$, lactate and ketone anions in the interstitial space; Figure 1). MCT expressed in the endothelial cell of blood vessels would participate in the transport of $\mathrm{H}^{+}$, lactate and ketone anions from the interstitial space to the intracellular space of the endothelial cells [56] (Figure 1). Further, MCT expressed in the endothelial cell also participates in the transport of $\mathrm{H}^{+}$, lactate and ketone anions to blood from the intracellular space of the endothelial cells [56] (Figure 1). NHE actively extrudes $\mathrm{H}^{+}$ from the intracellular space of the endothelial space to blood, keeping the low intracellular $\mathrm{H}^{+}$concentration of the endothelial cell for the driving force of $\mathrm{H}^{+}$, lactate and ketone anion transport [56] (Figure 1). Thus, $\mathrm{H}^{+}$, lactate and ketone anions are transported from the intracellular space of myocyte, adipocyte, and hepatocyte to blood via the interstitial space. In addition to the transcellular transport pathway, the paracellular pathway is also available for the passive transport of small-sized electrolytes into blood from the interstitial space. The paracellular pathway is permeable to small-sized electrolytes, such as $\mathrm{Na}^{+}, \mathrm{K}^{+}, \mathrm{H}^{+}$, and $\mathrm{Cl}^{-}$. However, it is unclear how large the transport capacity of $\mathrm{Na}^{+}, \mathrm{K}^{+}, \mathrm{H}^{+}$, and $\mathrm{Cl}^{-}$is compared with that of the transcellular pathway. Therefore, in this review article, we just introduce that the paracellular pathway for the passive transport of small-seized electrolytes, such as $\mathrm{Na}^{+}, \mathrm{K}^{+}$, $\mathrm{H}^{+}$, and $\mathrm{Cl}^{-}$, is available across the interstitial space and blood.

One of the most important points is that the interstitial fluid could easily turn to acidic condition due to poor buffering factors such as proteins in contrast to intracellular fluid and blood (Figures 1 and 2). Growing evidence suggests that the interstitial fluid acidosis could strongly contribute to the development of metabolic diseases. We have shown that before the development of diabetic symptoms, Otsuka Long-Evans Tokushima Fatty (OLETF) rats showed lower interstitial fluid $\mathrm{pH}$ in ascites and metabolic tissues than the normal pH (7.40) [57]. Notably, the interstitial fluid has little buffering capacity unlike the cytosol or blood that has a lot of proteins, strong buffering factors of proton [1,58,59] (Figure 2). The $\mathrm{pH}$ of blood (arterial blood $\mathrm{pH}$ ) is strictly regulated within the range of 7.35-7.45 as blood has strong $\mathrm{pH}$ buffers such as albumin and $\mathrm{Hb}$ (Figure 2). On the other hand, interstitial fluids have only relatively weak $\mathrm{pH}$ buffers, bicarbonate and phosphate. Therefore, the $\mathrm{pH}$ of interstitial fluids has relatively variable $\mathrm{pH}$ values compared with the blood pH (Figure 2).

We have demonstrated, in an in vitro study, that low extracellular $\mathrm{pH}$ shows an inhibitory effect on the insulin signaling pathway in the L6 rat myotubes [60]. The binding affinity of insulin to its receptor, the insulin-induced phosphorylation level of insulin receptor, and the phosphorylation levels of Akt, a downstream target of the intracellular insulin signaling, are significantly diminished in lower extracellular $\mathrm{pH}$ along with the reduction in glucose uptake [60]. These in vitro observations indicate that insulin resistance would be caused by the low extracellular $\mathrm{pH}$ in the skeletal muscle cells. Therefore, the interstitial fluid $\mathrm{pH}$ in metabolic tissues readily changes (Figure 1) and may contribute to the onset of insulin resistance via diminution of insulin affinity to its receptor [1] (Figure 3). Other studies [61-63] have shown that the amount of organic acid production is correlated to insulin sensitivity in both type 2 diabetes patients and healthy subjects. A cross-sectional study of over 1000 subjects [61] has indicated that insulin sensitivity and urine $\mathrm{pH}$ are lower as body weight and waist circumference increase. The $\mathrm{pH}$ of $24-\mathrm{h}$ urine in patients with metabolic syndrome was

\section{Acidification $\Rightarrow$ Insulin resistance $\Rightarrow$ Hyperglycemia}

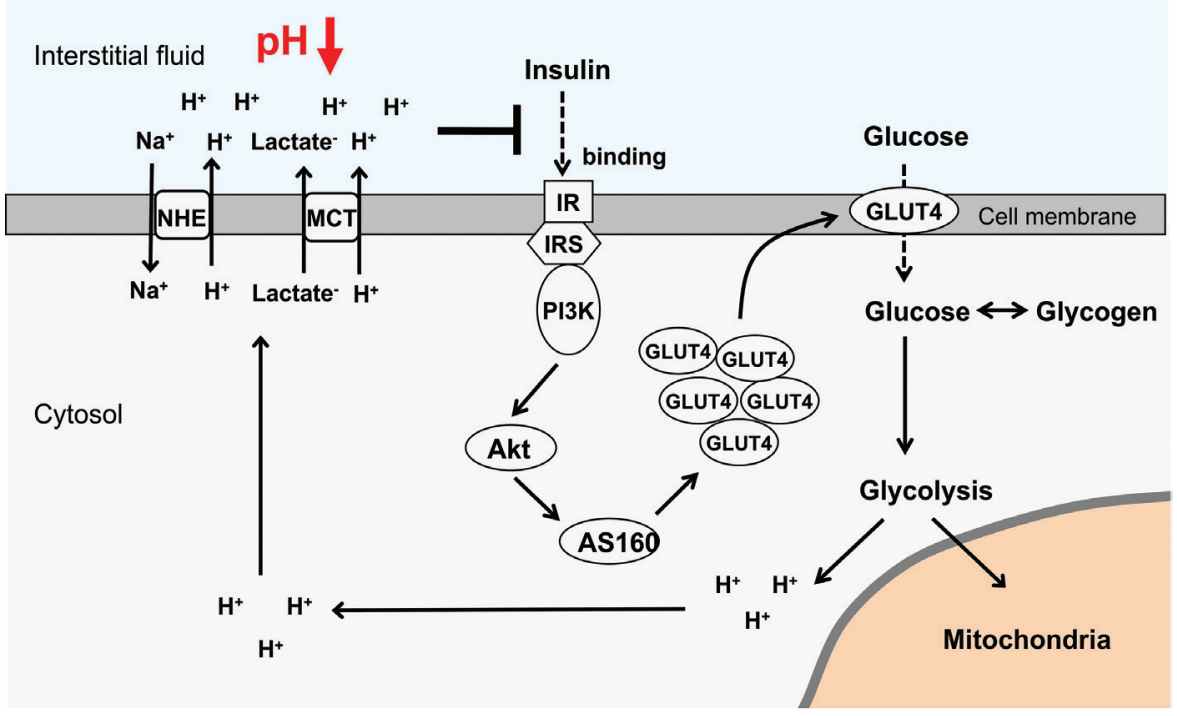

Figure 3 Glucose metabolism impairment and interstitial pH reduction in skeletal muscle cells. Glucose and glycogen are used as major energy substrates. Excess glucose/glycogen utilization and aerobic metabolism impairment cause lactic acid production through the glycolysis pathway. Further, binding affinity of insulin to its receptor is diminished with $\mathrm{pH}$ reduction in interstitial fluid. This leads to suppression of insulin signaling activity and glucose uptake via Glucose Transporter 4 (GLUT4). Therefore, low interstitial fluid pH causes insulin resistance and hyperglycemia via diminution of insulin affinity to its receptor in skeletal muscle cells. IR, insulin receptor; IRS, insulin receptor substrate; PI3K, phosphoinositide-3-kinase; AS160, Akt substrate of $160 \mathrm{kDa}$; MCT, monocarboxylate transporter; $\mathrm{NHE}, \mathrm{Na}^{+} / \mathrm{H}^{+}$exchanger. 
significantly lower than that in the normal subjects and the mean value of 24-h urine $\mathrm{pH}$ negatively correlates to the number of metabolic syndrome abnormalities $[62,63]$. Lower insulin sensitivity is observed in lower levels of serum bicarbonate and higher levels of anions resulting from metabolic acidosis [64]. Patients with obesity and type 2 diabetes show hyperlactacidemia [53], supporting that insulin sensitivity correlates to acidic condition. Even in healthy subjects, the urine acid level could be an independent risk factor for the development of type 2 diabetes [65].

Hypertension, high blood glucose levels, visceral obesity, and dyslipidemia are frequently associated with insulin resistance, one of the major symptoms of metabolic disorders [66]. However, the mechanistic links between insulin resistance and hypertension is still unclear. Insulin resistance causes hyperinsulinemia due to insufficiency of insulin action in muscles with low $\mathrm{pH}$ of the interstitial fluid [1]. However, insulin effectively acts on its receptor in the kidney with normal $\mathrm{pH}$ of the interstitial fluid owing to rich blood flow [1], leading to an extensive reabsorption of $\mathrm{Na}^{+}$via activation of epithelial $\mathrm{Na}^{+}$channels activated by insulin [67]. The large amount of $\mathrm{Na}^{+}$reabsorption causes volume-expanded hypertension [1]. Further, high intake of salt $(\mathrm{NaCl})$ causes volumeexpanded hypertension, decreasing the interstitial fluid $\mathrm{pH}$ due to large production of ATP spent for extrusion of $\mathrm{Na}^{+}$from muscle cells (Figure 4). This drop of the interstitial fluid $\mathrm{pH}$ due to high intake of $\mathrm{Na}^{+}$causes insulin resistance [1].

The high $\mathrm{Na}^{+}$intake would cause an increase in the $\mathrm{Na}^{+}$content in the interstitial space, elevating the volume of interstitial fluid via augmentation of the passive water movement into the interstitial space driven by an increase in the $\mathrm{Na}^{+}$-induced osmotic pressure of the interstitial fluid, and the expansion of the interstitial fluid volume disturbs the lymphatic flow resulting in a vicious circle associated with elevation of the interstitial fluid volume. The edema caused by other reasons, such as a low protein level in blood, hypertension, and so on, also shows a phenomenon similar to the high $\mathrm{Na}^{+}$-intake-caused edema. However, in cases of a low blood

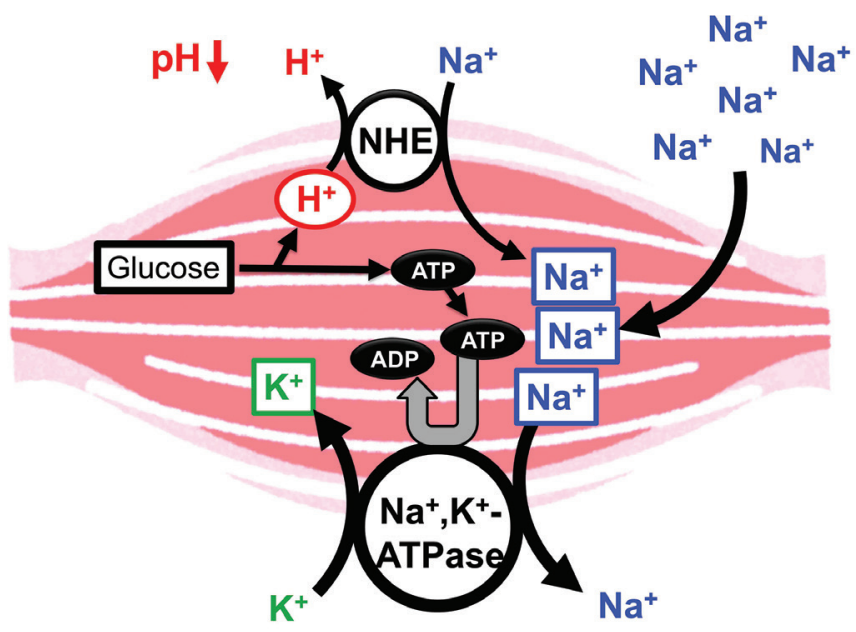

Figure 4 Possible molecular mechanism of the high salt intake-induced interstitial $\mathrm{pH}$ drop. High salt intake results in consumption of ATP required for the $\mathrm{Na}^{+}, \mathrm{K}^{+}$-ATPase for extrusion of the high-leveled intracellular $\mathrm{Na}^{+}$. To maintain the ATP level in the intracellular space, a lot of ATP should be produced associated with production of $\mathrm{H}^{+}$, reducing the interstitial pH. Modified from Figure 7 in Marunaka [1]. proteins and hypertension, the water movement between the inside of blood capillary and the interstitial is disturbed as described below. A low protein level in blood lowers the colloid pressure existing in the blood capillary, reducing the water movement into blood capillaries from interstitial fluid spaces across the walls of blood capillaries associated with disturbance of metabolite collection [68-71]. This means that if the interstitial fluid has strong $\mathrm{pH}$ buffers, such as proteins, the driving force of water movement into blood capillaries from interstitial fluid spaces reduces, resulting in edema. On the other hand, hypertension increases the water movement from blood capillaries into interstitial fluids across the walls of blood capillaries, resulting in edema [70]. Further, we should consider the paracellular diffusion caused by the leakiness of the blood capillary wall, leading to an increase in the protein content in the interstitial fluid associated with expansion of the interstitial fluid volume, the edema [70]. The $\mathrm{pH}$ regulation of interstitial fluid should be discussed carefully considering the cause of the edema. In cases of low blood proteins and hypertension, the composition of interstitial fluids would not be drastically changed as only the driving force of water movement changes with little change of permeabilities to solutes between blood and interstitial fluids including $\mathrm{pH}$ buffers such as bicarbonate and phosphate. Therefore, the $\mathrm{pH}$ regulation of interstitial fluids would not be drastically changed under the edema caused by low blood proteins and hypertension. On the other hand, in case of edema caused by the leakiness of the blood capillary wall, proteins such as albumin in blood would appear in the interstitial fluid, elevating the $\mathrm{pH}$ buffer capacity. Therefore, the $\mathrm{pH}$ regulation of interstitial fluids would be more strictly conducted.

Insulin resistance is the most important pathogenesis of type 2 diabetes and also develops cancer and cardiovascular diseases [72,73]. Thus, the fluid $\mathrm{pH}$ disturbance can cause abnormal metabolic regulation in a predisease state. Our observation [74] indicated that diabetic OLETF rats (26 weeks of age) show a lower interstitial pH than normal Wistar rats around the hippocampus, an important region for memory [75]. A high risk of developing dementia and Alzheimer's disease has been reported in diabetic patients [76] who might have experience of defective memory functions. Insulin has an essential role in survival of the neuron within central nervous system [77]. The deficiency of insulin action causes unstable fluctuating blood glucose levels, leading to apoptosis and energy starvation [78-80]. Further, the fluctuation of blood glucose levels also forms neurotic plaques and neurofibrillary tangles, which produce the hallmark lesions of Alzheimer's disease, and alters acetylcholine levels in the hippocampus [78-80]. The findings mentioned above lead us to an idea that: (1) the interstitial fluid $\mathrm{pH}$ is an essentially important key factor for metabolic homeostasis and (2) the maintenance of the interstitial fluid $\mathrm{pH}$ within the normal range or the recovery of the interstitial $\mathrm{pH}$ to the normal range is one of the novel therapeutic targets for metabolic brain disorders.

\section{5. $\mathrm{pH}$ REGULATION BY APPROPRIATE DIETS AND FUNCTIONAL FOOD FACTORS}

It is widely known that appropriate diet is an important habituation for the prevention of onset and progression of noncommunicable diseases. The maintenance of fluid $\mathrm{pH}$ homeostasis can be involved in the diet-induced metabolic health. Several intervention studies in humans have shown that fruit and vege- 
table-rich foods improve the acid-base balance and raise the urinary $\mathrm{pH}$; these foods are collectively referred to as the alkaline diet [81]. Originally, food with alkaline characteristics has been recognized to contain abundant alkaline ash generated by food combustion. Furthermore, it has been suggested as acid excretion level into urine because urinary acid reflects acid-base balance of fluid in the whole body. To evaluate alkaline function of foods, acid excretion level into urine has been expressed as the potential renal acid loads that are calculated using excretion amounts of sulfate, chloride, phosphorus, sodium, potassium, calcium, mag- nesium, and organic acids, estimated from consumed foods and body size [82]. Subsequently, various fruits and vegetables were categorized as lower potential renal acid load (PRAL) foods and could induce the body fluid to alkaline state (Table 2). In contrast, animal food products showed higher PRAL levels. In addition, several strategies for functional examination have been developed on the basis of the concepts mentioned above (Figure 5). Various bioactive factors present in natural foods such fruits and vegetables can have potential alkaline functions that contribute to $\mathrm{pH}$ homeostasis through several mechanisms (Table 2).

Table 2 Major alkaline foods and functional compounds

\begin{tabular}{|c|c|c|}
\hline Foods & Major nutrients/compounds & Function \\
\hline \multicolumn{3}{|l|}{ Lower PRAL vegetables } \\
\hline $\begin{array}{l}\text { Spinach, celery, eggplant, tomato, } \\
\text { green beans }\end{array}$ & $\begin{array}{l}\text { Ascorbate, potassium, calcium, magnesium, } \\
\text { flavone, } \beta \text {-carotene, lycopene }\end{array}$ & $\begin{array}{l}\text { Reduction of acid load in the } \\
\text { whole body }\end{array}$ \\
\hline \multicolumn{3}{|l|}{ Lower PRAL fruits and drinks } \\
\hline $\begin{array}{l}\text { Raisins, black currents, banana, apricots, } \\
\text { orange, apple }\end{array}$ & $\begin{array}{l}\text { Ascorbate, potassium, calcium, magnesium, } \\
\text { anthocyanin, procyanidin, citrate, malate }\end{array}$ & $\begin{array}{l}\text { Reduction of acid load in the } \\
\text { whole body }\end{array}$ \\
\hline Red wine & Anthocyanin, resveratrol & \\
\hline \multicolumn{3}{|l|}{ Organic weak acid-rich foods } \\
\hline Citrus, plum, vinegar & Citrate, acetate, malate & Buffering action \\
\hline Fermented foods & Propionate, butylate & \\
\hline \multicolumn{3}{|l|}{ Functional amino acid-rich foods } \\
\hline Chicken, fish & $\beta$-alanine & Buffering action \\
\hline Soy, meat, fish, melon, watermelon, cucumber & Arginine, citrulline & Vasodilation \\
\hline \multicolumn{3}{|l|}{ Mitochondria activator foods } \\
\hline Green tea, onion, apple, berry, red wine, salmon, shrimp & Catechin, quercetin, anthocyanin, resveratrol, astaxanthin & Reduction of acid production \\
\hline
\end{tabular}

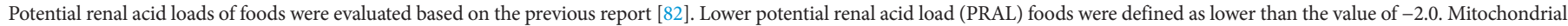
activator food was defined as one that activates mitochondrial biogenesis and mitochondrial metabolic enzymes.

Functional Targets for Dietary Alkaline Foods in Metabolic Organs

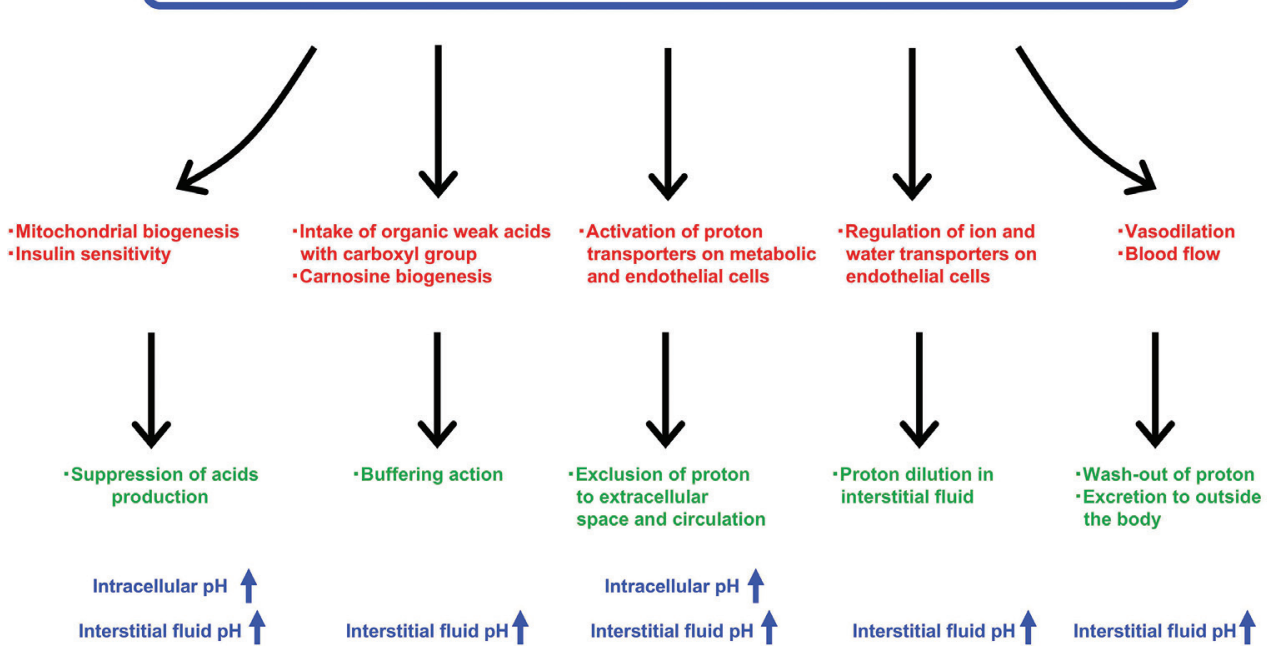

Figure 5 Research strategies for alkaline foods in metabolic organs. Bioactive factors contained in natural foods have potential benefits to prevent fluid acidification. Improvement of mitochondrial biogenesis and insulin sensitivity is one of the most important research strategies to suppress excess production of organic acids. Intake of organic weak acids with carboxyl group may also improve circulating and cellular pH-buffering capacities. In addition, acceleration of transporter-mediated proton excretion from cytosol to extracellular space across the plasma membrane on metabolic and endothelial cells can be another mechanism for preventing intracellular acidosis. Regulating water transport of the plasma membrane also contributes to the maintenance of $\mathrm{pH}$ homeostasis by diluting proton concentration in the fluid. Several food factors improve peripheral microcirculation through vasodilation, facilitating wash-out of proton for prevention of acidification. 
A research strategy is to suppress excess production of lactic acids and ketone bodies by mitochondrial biogenesis for insulin sensitivity improvement in myocyte and hepatocyte. Several food factors including quercetin, catechin, anthocyanin, and astaxanthin enhance the Krebs cycle function by accelerating the entry of fatty acids from cytosol into mitochondria in the muscle cells. This is achieved through the elevation of activity and number of mitochondria in the muscle cells [83-87]. As the major energy substrates are carbohydrates and lipids, the lipid utilization compensates and decreases the utilization of carbohydrates, further decreasing the lactic acid production through the glycolysis pathway. On the other hand, enhancement of insulin sensitivity in metabolic organs maintains normal glucose metabolism. This leads to suppression of excess ketone body production from free fatty acids in hepatocyte, which also contributes to maintenance of $\mathrm{pH}$ homeostasis.

Circulating and tissue-buffering capacities are also improved by intake of organic weak acids such citrate, acetate, and malate [1] (see the detail shown in Figure 6). Indeed, dietary citrate has been shown to improve the circulating and intramuscular-buffering capacities $[88,89]$. The dietary organic acids are dissociated into anions and proton, and only the part of anions is absorbed from the intestinal lumen into circulation [1]. Thereafter, the organic anions function as $\mathrm{pH}$-buffering factors in the peripheral tissues [1]. A dipeptide, carnosine ( $\beta$-alanyl-L-histidine) may also act as a buffering factor and is found in high concentration in the skeletal muscle. The intake of $\beta$-alanine, the limiting precursor in carnosine synthesis, likely increases the endogenous $\mathrm{H}^{+}$-buffering capacity [90].

Accelerating excretion of protons from cytosol to extracellular space via transporters located on the plasma membrane can be another mechanism for preventing intracellular acidosis. Several food factors improve peripheral microcirculation through vasodilation, resulting in facilitation of washout of proton. For example, arginine and citrulline amino acids promote nitric oxide production in endothelial cells in blood vessels, leading to the improved capillary circulation and acid removal [91]. Accelerating the excretion of protons from cytosol to the extracellular space or into circulation via transporters located on the plasma membrane can be another mechanism of the functional food factors for preventing intracellular acidosis. Many studies report that exercise intervention increases MCT1 and MCT4 levels in the skeletal muscle [92-95], whereas the effect of food factors on MCT or other proton transporters remains unclear. However, recent reports show that MCTs in skeletal muscle are upregulated by chlorella and black ginger extracts in animal and culture studies [96], suggesting the contribution of dietary foods in the maintenance of $\mathrm{pH}$ homeostasis via proton transport. In addition to the proton transport, dilution of proton concentration may contribute to maintenance of the interstitial fluid $\mathrm{pH}$. Activation of water transport from circulation into interstitial fluid results in the proton dilution, leading to suppression of fluid acidification. However, as the premise, water transport depends on osmolytes such electrolytes and proteins contained in fluids because water is basically transported with osmotic pressure gradient between interstitial fluid and plasma. Therefore, it would be important to regulate both osmolytes and water transports. In the future, further diet intervention studies focusing on efficient proton and water transports should be developed.

Combined administration of food factors has more beneficial effects [97-99] with some evidence that supplementation of single nutrients could not clearly show their beneficial action on insulin resistance, cardiovascular risk, and physical performance $[100,101]$. The information suggests that intake of multiple nutrients would be more effective than that of a single bioactive factor. Propolis is a honeybee-collected natural product derived from plant resins. Various types of compounds are contained in propolis such as polyphenols, phenolic aldehydes, sesquiterpene quinines, coumarins, amino acids, steroids, and inorganic compounds

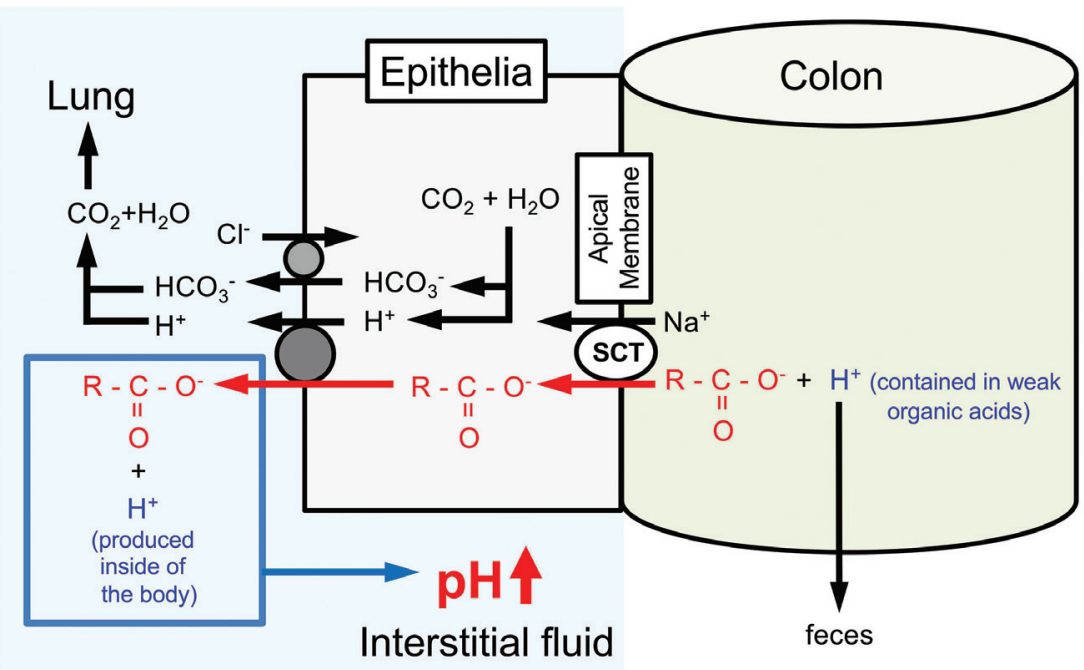

Figure 6 Action of oral intake of weak organic acids with carboxyl groups contained in foods on regulation of the interstitial fluid pH. By consuming weak organic 'acid' containing a carboxyl part ( $\mathrm{R}-\mathrm{COO}^{-}$) only the carboxyl part (R-COO-) is absorbed via sodium-coupled carboxylate transporters expressed in the apical membrane of the intestinal epithelium without $\mathrm{H}^{+}$in the weak organic 'acid'. Carboxyl groups incorporated into the intracellular space of the intestinal epithelium are transported from the intracellular space to the interstitial space (the extracellular space) of the intestinal epithelium via $\mathrm{H}^{+}$-coupled Monocarboxylate Transporters (MCT). $\mathrm{H}^{+}$contained in weak organic acids is excreted into feces. Based on the phenomena, weak organic acids behave as 'bases' by combing with $\mathrm{H}^{+}$produced in the body, elevating $\mathrm{pH}$. This means that intake of weak organic acids elevates $\mathrm{pH}$ by increasing $\mathrm{pH}$ buffers in the interstitial fluid. Modified from Figure 5 in Marunaka [1]. 
[102]. Our previous report [57] indicates that propolis shows beneficial effects on metabolic disorders such as abnormal blood glucose levels in young (18 weeks of age) OLETF type 2 diabetic model rats, which show symptoms as type 2 diabetes mellitus such as obesity, hyperphagia, decreased glucose infusion rate in euglycemic clamp at 16-18 weeks of age, and hyperinsulinemia around 25 weeks of age responding to an intravenous glucose infusion [103,104]. Thus, our study [57] suggests that propolis is a compound showing beneficial, preventive action on symptoms of type 2 diabetes mellitus at early stages of the development of insulin resistance. Furthermore, this study [57] clearly reports that the $\mathrm{pH}$ of ascites and interstitial fluids around metabolic tissues is improved (elevated) by the intake of propolis compared with normal diet (without propolis intake), suggesting a possibility that dietary propolis suppresses the production of organic acids and/or elevates the $\mathrm{pH}$-buffering capacity in those tissues. In addition, we have shown in a double-blind randomized placebo-controlled study in type 2 diabetic patients that the supplementation of propolis for 8 weeks has prevented the worsening of blood uric acid and improved the estimated glomerular filtration rate [104]. Therefore, propolis may be a useful compound to improve glucose metabolism associated with the prevention of acidic state. On the other hand, Japanese traditional herbal medicine is also known to improve various types of metabolic disorder symptoms including diabetes mellitus. Ninjin'yoeito (NYT), a Japanese traditional herbal medicine, consists of 12 species of crude drugs: rehmannia root, Japanese angelica root, atractylodes rhizome, poria sclerotium, ginseng, cinnamon bark, polygala root, peony root, citrus unshiu peel, astragalus root, glycyrrhiza, and schisandra fruit. NYT has also been shown to improve insulin resistance by elevating the interstitial fluid $\mathrm{pH}$ possibly via an increase in sodium-coupled monocarboxylate transporter 1 expressed in the colon, which transports only the part of carboxyl group without $\mathrm{H}^{+}$, leading to an increase in $\mathrm{pH}$-buffering capacity $[1,105,106]$ (Figure 6).

In the future, further studies should be conducted to gather more evidence on the effectiveness of alkaline foods against metabolic disorders like diabetes mellitus.

\section{CONCLUSION}

Regulating organic acid production and proton clearance is important for the prevention of acidic conditions in body fluids, and for the improvement of metabolic dysfunction and physical performance. Interstitial fluid $\mathrm{pH}$, more than the intracellular and blood $\mathrm{pH}$, can readily be reduced by acid stress, which may lead to the development of metabolic diseases. Appropriate diet and several bioactive factors have the potential to maintain $\mathrm{pH}$, which might be associated with the activation of proton transporters, such as MCT and NHE, and to improve the pH-buffering capacity and blood flow. However, further studies are required to examine the contributions of various diets to $\mathrm{pH}$ homeostasis and metabolic health.

\section{CONFLICTS OF INTEREST}

The authors declare they have no conflicts of interest.

\section{AUTHOR CONTRIBUTIONS}

W.A. and Y.M. planned the whole designs of the article and wrote the manuscript. X.Z. and J.B.X. contributed to validation of the contents.

\section{ACKNOWLEDGMENTS}

This work was supported by Grants-in-Aid from Japan Society of the Promotion of Science (17H02176 to W.A. and 18H03182 to Y.M.).

\section{REFERENCES}

[1] Marunaka Y. The proposal of molecular mechanisms of weak organic acids intake-induced improvement of insulin resistance in diabetes mellitus via elevation of interstitial fluid $\mathrm{pH}$. Int J Mol Sci 2018;19:pii: E3244.

[2] Osuna-Padilla IA, Leal-Escobar G, Garza-García CA, RodríguezCastellanos FE. Dietary acid load: mechanisms and evidence of its health repercussions. Nefrología 2019;39:343-54.

[3] Rizzoli R, Biver E, Bonjour JP, Coxam V, Goltzman D, Kanis JA, et al. Benefits and safety of dietary protein for bone health - an expert consensus paper endorsed by the European Society for Clinical and Economical Aspects of Osteopororosis, Osteoarthritis, and Musculoskeletal Diseases and by the International Osteoporosis Foundation. Osteoporos Int 2018;29:1933-48.

[4] Williams RS, Heilbronn LK, Chen DL, Coster ACF, Greenfield JR, Samocha-Bonet D. Dietary acid load, metabolic acidosis and insulin resistance - lessons from cross-sectional and overfeeding studies in humans. Clin Nutr 2016;35:1084-90.

[5] Williams RS, Kozan P, Samocha-Bonet D. The role of dietary acid load and mild metabolic acidosis in insulin resistance in humans. Biochimie 2016;124: 171-7.

[6] Sun N, Avdeef A. Biorelevant $\mathrm{pK}(\mathrm{a})\left(37^{\circ} \mathrm{C}\right)$ predicted from the $2 \mathrm{D}$ structure of the molecule and its $\mathrm{pK}(\mathrm{a})$ at $25^{\circ} \mathrm{C}$. J Pharm Biomed Anal 2011;56:173-82.

[7] Brooks GA. The science and translation of lactate shuttle theory. Cell Metab 2018;27:757-85.

[8] Calì C, Tauffenberger A, Magistretti P. The strategic location of glycogen and lactate: from body energy reserve to brain plasticity. Front Cell Neurosci 2019;13:82.

[9] Gillies RJ, Pilot C, Marunaka Y, Fais S. Targeting acidity in cancer and diabetes. Biochim Biophys Acta Rev Cancer 2019;1871:273-80.

[10] Pillai SR, Damaghi M, Marunaka Y, Spugnini EP, Fais S, Gillies RJ. Causes, consequences, and therapy of tumors acidosis. Cancer Metastasis Rev 2019;38:205-22.

[11] Ghimire P, Kaul P, Dhamoon AS. Ketoacidosis. Treasure Island, Florida, USA: StatPearls Publishing LLC; 2019.

[12] Newman JC, Verdin E. $\beta$-hydroxybutyrate: a signaling metabolite. Annu Rev Nutr 2017;37:51-76.

[13] Garcia CK, Goldstein JL, Pathak RK, Anderson RGW, Brown MS Molecular characterization of a membrane transporter for lactate, pyruvate, and other monocarboxylates: implications for the Cori cycle. Cell 1994;76:865-73.

[14] Halestrap AP. The monocarboxylate transporter family-structure and functional characterization. IUBMB Life 2012;64:1-9.

[15] Luo F, Zou Z, Liu X, Ling M, Wang Q, Wang Q, et al. Enhanced glycolysis, regulated by HIF-1a via MCT-4, promotes inflammation in arsenite-induced carcinogenesis. Carcinogenesis 2017;38:615-26. 
[16] Poole RC, Halestrap AP. Transport of lactate and other monocarboxylates across mammalian plasma membranes. Am J Physiol 1993;264:C761-C82.

[17] Sprowl-Tanio S, Habowski AN, Pate KT, McQuade MM, Wang $\mathrm{K}$, Edwards RA, et al. Lactate/pyruvate transporter MCT-1 is a direct Wnt target that confers sensitivity to 3-bromopyruvate in colon cancer. Cancer Metab 2016;4:20.

[18] Burckhardt G, Di Sole F, Helmle-Kolb C. The $\mathrm{Na}^{+} / \mathrm{H}^{+}$exchanger gene family. J Nephrol 2002;15:S3-S21.

[19] Loh SH, Chen WH, Chiang CH, Tsai CS, Lee GC, Jin JS, et al. Intracellular $\mathrm{pH}$ regulatory mechanism in human atrial myocardium: functional evidence for $\mathrm{Na}^{+} / \mathrm{H}^{+}$exchanger and $\mathrm{Na}^{+} / \mathrm{HCO}_{3}^{-}$ symporter. J Biomed Sci 2002;9:198-205.

[20] Ruffin VA, Salameh AI, Boron WF, Parker MD. Intracellular pH regulation by acid-base transporters in mammalian neurons. Front Physiol 2014;5:43.

[21] Casey JR, Grinstein S, Orlowski J. Sensors and regulators of intracellular pH. Nat Rev Mol Cell Biol 2010;11:50-61.

[22] Juel C. Intracellular $\mathrm{pH}$ recovery and lactate efflux in mouse soleus muscles stimulated in vitro: the involvement of sodium/ proton exchange and a lactate carrier. Acta Physiol Scand 1988; 132:363-71.

[23] Juel C. Lactate/proton co-transport in skeletal muscle: regulation and importance for $\mathrm{pH}$ homeostasis. Acta Physiol Scand 1996; 156:369-74.

[24] Bonen A, Baker SK, Hatta H. Lactate transport and lactate transporters in skeletal muscle. Can J Appl Physiol 1997;22:531-52.

[25] Juel C. Regulation of cellular $\mathrm{pH}$ in skeletal muscle fiber types, studied with sarcolemmal giant vesicles obtained from rat muscles. Biochim Biophys Acta 1995;1265:127-32.

[26] Eledrisi MS, Alshanti MS, Shah MF, Brolosy B, Jaha N. Overview of the diagnosis and management of diabetic ketoacidosis. Am J Med Sci 2006;331:243-51.

[27] Fafournoux P, Demigné C, Rémésy C. Mechanisms involved in ketone body release by rat liver cells: influence of $\mathrm{pH}$ and bicarbonate. Am J Physiol 1987;252:G200-G8.

[28] Roth DA, Brooks GA. Lactate transport is mediated by a membranebound carrier in rat skeletal muscle sarcolemmal vesicles. Arch Biochem Biophys 1990;279:377-85.

[29] Juel C. Muscle lactate transport studied in sarcolemmal giant vesicles. Biochim Biophys Acta 1991;1065:15-20.

[30] McDermott JC, Bonen A. Lactate transport by skeletal muscle sarcolemmal vesicles. Mol Cell Biochem 1993;122:113-21.

[31] Bonen A, Tonouchi M, Miskovic D, Heddle C, Heikkila JJ, Halestrap AP. Isoform-specific regulation of the lactate transporters MCT1 and MCT4 by contractile activity. Am J Physiol Endocrinol Metab 2000;279:E1131-E8.

[32] Brooks GA, Dubouchaud H, Brown M, Sicurello JP, Butz CE. Role of mitochondrial lactate dehydrogenase and lactate oxidation in the intracellular lactate shuttle. Proc Natl Acad Sci USA 1999;96:1129-34.

[33] Pilegaard H, Terzis G, Halestrap A, Juel C. Distribution of the lactate $/ \mathrm{H}^{+}$transporter isoforms MCT1 and MCT4 in human skeletal muscle. Am J Physiol 1999;276:E843-E8.

[34] Garcia CK, Brown MS, Pathak RK, Goldstein JL. cDNA cloning of MCT2, a second monocarboxylate transporter expressed in different cells than MCT1. J Biol Chem 1995;270:1843-9.

[35] Wakabayashi S, Shigekawa M, Pouyssegur J. Molecular physiology of vertebrate $\mathrm{Na}^{+} / \mathrm{H}^{+}$exchangers. Physiol Rev 1997;77:51-74.

[36] Orlowski J, Grinstein S. Diversity of the mammalian sodium/proton exchanger SLC9 gene family. Pflügers Arch 2004;447:549-65.
[37] Donowitz M, Tse CM. Molecular physiology of mammalian epithelial $\mathrm{Na}^{+} / \mathrm{H}^{+}$exchangers NHE2 and NHE3. Curr Top Membr 2000;50:437-98.

[38] Authier B, Albrand JP, Decorps M, Reutenauer H, Rossi A. Disruption of muscle energy metabolism due to intense ischaemic exercise: a 31P NMR study in rats. Physiol Chem Phys Med NMR 1987;19:83-93.

[39] Fitts RH. Cellular mechanisms of muscle fatigue. Physiol Rev 1994;74:49-94.

[40] Sumi S, Mineo I, Kono N, Shimizu T, Nonaka K, Tarui S. Decreases in hepatic fructose-2,6-bisphosphate level and fructose6-phosphate, 2-kinase activity in diabetic mice: a close relationship to the development of ketosis. Biochem Biophys Res Commun 1984;120:103-8.

[41] Lemieux G, Aranda MR, Fournel P, Lemieux C. Renal enzymes during experimental diabetes mellitus in the rat. Role of insulin, carbohydrate metabolism, and ketoacidosis. Can J Physiol Pharmacol 1984;62:70-5.

[42] Gil J, Carreras J, Bartrons R. Effects of diabetes on fructose 2, 6-P2, glucose 1,6-P2 and 6-phosphofructo 2-kinase in rat liver. Biochem Biophys Res Commun 1986;136:498-503.

[43] Mainwood GW, Renaud JM. The effect of acid-base balance on fatigue of skeletal muscle. Can J Physiol Pharmacol 1985;63:403-16.

[44] Lännergren J, Westerblad H. Force decline due to fatigue and intracellular acidification in isolated fibres from mouse skeletal muscle. J Physiol 1991;434:307-22.

[45] Rahman B, Schneider HP, Bröer A, Deitmer JW, Bröer S. Helix 8 and helix 10 are involved in substrate recognition in the rat monocarboxylate transporter MCT1. Biochemistry 1999;38:11577-84.

[46] Merezhinskaya N, Fishbein WN, Davis JI, Foellmer JW. Mutations in MCT1 cDNA in patients with symptomatic deficiency in lactate transport. Muscle Nerve 2000;23:90-7.

[47] Fishbein WN. Lactate transporter defect: a new disease of muscle. Science 1986;234:1254-6.

[48] Juel C, Honig A, Pilegaard H. Muscle lactate transport studied in sarcolemmal giant vesicles: dependence on fiber type and age. Acta Physiol Scand 1991;143:361-6.

[49] McCullagh KJ, Bonen A. Reduced lactate transport in denervated rat skeletal muscle. Am J Physiol 1995;268:R884-R8.

[50] Py G, Lambert K, Perez-Martin A, Raynaud E, Préfaut C, Mercier J. Impaired sarcolemmal vesicle lactate uptake and skeletal muscle MCT1 and MCT4 expression in obese Zucker rats. Am J Physiol Endocrinol Metab 2001;281:E1308-E15.

[51] Lengacher S, Nehiri-Sitayeb T, Steiner N, Carneiro L, Favrod C, Preitner F, et al. Resistance to diet-induced obesity and associated metabolic perturbations in haploinsufficient monocarboxylate transporter 1 mice. PLoS One 2013;8:e82505.

[52] Chatel B, Bendahan D, Hourdé C, Pellerin L, Lengacher S, Magistretti P, et al. Role of MCT1 and CAII in skeletal muscle $\mathrm{pH}$ homeostasis, energetics, and function: in vivo insights from MCT1 haploinsufficient mice. FASEB J 2017;31:2562-75.

[53] Reaven GM, Hollenbeck C, Jeng CY, Wu MS, Ida Chen YD. Measurement of plasma glucose, free fatty acid, lactate, and insulin for $24 \mathrm{~h}$ in patients with NIDDM. Diabetes 1988;37:1020-4.

[54] Santos JL, Cataldo LR, Cortés-Rivera C, Bravo C, Díaz-Casanova L, Martínez JA, et al. Plasma lactate and leukocyte mitochondrial DNA copy number as biomarkers of insulin sensitivity in nondiabetic women. J Physiol Biochem 2019;75:285-97.

[55] Geisler CE, Ghimire S, Bogan RL, Renquist BJ. Role of ketone signaling in the hepatic response to fasting. Am J Physiol Gastrointest Liver Physiol 2019;316:G623-G31. 
[56] Pérez-Escuredo J, Van Hée VF, Sboarina M, Falces J, Payen VL, Pellerin L, et al. Monocarboxylate transporters in the brain and in cancer. Biochim Biophys Acta 2016;1863:2481-97.

[57] Aoi W, Hosogi S, Niisato N, Yokoyama N, Hayata H, Miyazaki $\mathrm{H}$, et al. Improvement of insulin resistance, blood pressure and interstitial $\mathrm{pH}$ in early developmental stage of insulin resistance in OLETF rats by intake of propolis extracts. Biochem Biophys Res Commun 2013;432:650-3.

[58] Fogh-Andersen N, Altura BM, Altura BT, Siggaard-Andersen O. Composition of interstitial fluid. Clin Chem 1995;41:1522-5.

[59] Aukland K, Fadnes HO. Protein concentration of interstitial fluid collected from rat skin by a wick method. Acta Physiol Scand 1973;88:350-8.

[60] Hayata H, Miyazaki H, Niisato N, Yokoyama N, Marunaka Y. Lowered extracellular $\mathrm{pH}$ is involved in the pathogenesis of skeletal muscle insulin resistance. Biochem Biophys Res Commun 2014;445:170-4.

[61] Otsuki M, Kitamura T, Goya K, Saito H, Mukai M, Kasayama S, et al. Association of urine acidification with visceral obesity and the metabolic syndrome. Endocr J 2011;58:363-7.

[62] Maalouf NM, Cameron MA, Moe OW, Adams-Huet B, Sakhaee $\mathrm{K}$. Low urine $\mathrm{pH}$ : a novel feature of the metabolic syndrome. Clin J Am Soc Nephrol 2007;2:883-8.

[63] Maalouf NM, Cameron MA, Moe OW, Sakhaee K. Metabolic basis for low urine $\mathrm{pH}$ in type 2 diabetes. Clin J Am Soc Nephrol 2010;5:1277-81.

[64] Farwell WR, Taylor EN. Serum bicarbonate, anion gap and insulin resistance in the National Health and Nutrition Examination Survey. Diabet Med 2008;25:798-804.

[65] Ohlson LO, Larsson B, Björntorp P, Eriksson H, Svärdsudd K, Welin L, et al. Risk factors for type 2 (non-insulin-dependent) diabetes mellitus. Thirteen and one-half years of follow-up of the participants in a study of Swedish men born in 1913. Diabetologia 1988;31:798-805.

[66] Fujita T. The metabolic syndrome in Japan. Nat Clin Pract Cardiovasc Med 2008;5:S15-S18.

[67] Marunaka Y, Hagiwara N, Tohda H. Insulin activates single amiloride-blockable $\mathrm{Na}$ channels in a distal nephron cell line (A6). Am J Physiol 1992;263:F392-F400.

[68] Nordström CH. Volume-targeted therapy of increased intracranial pressure. Acta Neurochir Suppl 2003;86:355-60.

[69] Curry FR. Microvascular solute and water transport. Microcirculation 2005;12:17-31.

[70] Levick JR, Michel CC. Microvascular fluid exchange and the revised Starling principle. Cardiovasc Res 2010;87:198-210.

[71] Reed RK, Rubin K. Transcapillary exchange: role and importance of the interstitial fluid pressure and the extracellular matrix. Cardiovasc Res 2010;87:211-17.

[72] Djiogue S, Nwabo Kamdje AH, Vecchio L, Kipanyula MJ, Farahna $\mathrm{M}$, Aldebasi Y, et al. Insulin resistance and cancer: the role of insulin and IGFs. Endocr Relat Cancer 2013;20:R1-R17.

[73] Aroor AR, Mandavia CH, Sowers JR. Insulin resistance and heart failure: molecular mechanisms. Heart Fail Clin 2012;8:609-17.

[74] Marunaka Y, Yoshimoto K, Aoi W, Hosogi S, Ikegaya H. Low pH of interstitial fluid around hippocampus of the brain in diabetic OLETF rats. Mol Cell Ther 2014;2:6.

[75] Packard MG, Goodman J. Factors that influence the relative use of multiple memory systems. Hippocampus 2013;23:1044-52.

[76] Mirza Z, Kamal MA, Buzenadah AM, Al-Qahtani MH, Karim S. Establishing genomic/transcriptomic links between Alzheimer's disease and type 2 diabetes mellitus by meta-analysis approach. CNS Neurol Disord Drug Targets 2014;13:501-16.

[77] Dudek H, Datta SR, Franke TF, Birnbaum MJ, Yao R, Cooper GM, et al. Regulation of neuronal survival by the serine-threonine protein kinase Akt. Science 1997;275:661-5.

[78] Rasgon N, Jarvik L. Insulin resistance, affective disorders, and Alzheimer's disease: review and hypothesis. J Gerontol A Biol Sci Med Sci 2004;59:178-83; discussion 184-92.

[79] Steen E, Terry BM, Rivera EJ, Cannon JL, Neely TR, Tavares R, et al. Impaired insulin and insulin-like growth factor expression and signaling mechanisms in Alzheimer's disease - is this type 3 diabetes? J Alzheimers Dis. 2005;7:63-80.

[80] Salas IH, De Strooper B. Diabetes and Alzheimer's disease: a link not as simple as it seems. Neurochem Res 2019;44:1271-8.

[81] Schwalfenberg GK. The alkaline diet: is there evidence that an alkaline $\mathrm{pH}$ diet benefits health? J Environ Public Health 2012;2012:727630.

[82] Remer T, Manz F. Potential renal acid load of foods and its influence on urine pH. J Am Diet Assoc 1995;95:791-7.

[83] Wu J, Gao W, Wei J, Yang J, Pu L, Guo C. Quercetin alters energy metabolism in swimming mice. Appl Physiol Nutr Metab 2012;37:912-22.

[84] Henagan TM, Lenard NR, Gettys TW, Stewart LK. Dietary quercetin supplementation in mice increases skeletal muscle $P G C 1 \alpha$ expression, improves mitochondrial function and attenuates insulin resistance in a time-specific manner. PLoS One 2014;9:e89365.

[85] Murase T, Haramizu S, Shimotoyodome A, Tokimitsu I, Hase T. Green tea extract improves running endurance in mice by stimulating lipid utilization during exercise. Am J Physiol Regul Integr Comp Physiol 2006;290:R1550-R6.

[86] Seymour EM, Tanone II, Urcuyo-Llanes DE, Lewis SK, Kirakosyan A, Kondoleon MG, et al. Blueberry intake alters skeletal muscle and adipose tissue peroxisome proliferator-activated receptor activity and reduces insulin resistance in obese rats. J Med Food 2011;14:1511-18.

[87] Yu T, Dohl J, Chen Y, Gasier HG, Deuster PA. Astaxanthin but not quercetin preserves mitochondrial integrity and function, ameliorates oxidative stress, and reduces heat-induced skeletal muscle injury. J Cell Physiol 2019;234:13292-302.

[88] Kowalchuk JM, Maltais SA, Yamaji K, Hughson RL. The effect of citrate loading on exercise performance, acid-base balance and metabolism. Eur J Appl Physiol Occup Physiol 1989;58:858-64.

[89] Ball D, Maughan RJ. The effect of sodium citrate ingestion on the metabolic response to intense exercise following diet manipulation in man. Exp Physiol 1997;82:1041-56.

[90] Varanoske AN, Hoffman JR, Church DD, Coker NA, Baker KM, Dodd SJ, et al. $\beta$-Alanine supplementation elevates intramuscular carnosine content and attenuates fatigue in men and women similarly but does not change muscle L-histidine content. Nutr Res 2017;48:16-25.

[91] Figueroa A, Wong A, Jaime SJ, Gonzales JU. Influence of L-citrulline and watermelon supplementation on vascular function and exercise performance. Curr Opin Clin Nutr Metab Care 2017;20:92-8.

[92] Dubouchaud H, Butterfield GE, Wolfel EE, Bergman BC, Brooks GA. Endurance training, expression, and physiology of LDH, MCT1, and MCT4 in human skeletal muscle. Am J Physiol Endocrinol Metab 2000;278:E571-E9.

[93] Baker SK, McCullagh KJA, Bonen A. Training intensity-dependent and tissue-specific increases in lactate uptake and MCT-1 in heart and muscle. J Appl Physiol (1985) 1998;84:987-94. 
[94] Bonen A, McCullagh KJA, Putman CT, Hultman E, Jones NL, Heigenhauser GF. Short-term training increases human muscle MCT1 and femoral venous lactate in relation to muscle lactate. Am J Physiol 1998;274:E102-E7.

[95] Toda K, Takeda S, Hitoe S, Nakamura S, Matsuda H, Shimoda H. Enhancement of energy production by black ginger extract containing polymethoxy flavonoids in myocytes through improving glucose, lactic acid and lipid metabolism. J Nat Med 2016;70:163-72.

[96] Lindström J, Ilanne-Parikka P, Peltonen M, Aunola S, Eriksson JG, Hemiö K, et al. Sustained reduction in the incidence of type 2 diabetes by lifestyle intervention: follow-up of the Finnish Diabetes Prevention Study. Lancet 2006;368:1673-9.

[97] Plantinga Y, Ghiadoni L, Magagna A, Giannarelli C, Franzoni F, Taddei S, et al. Supplementation with vitamins $\mathrm{C}$ and $\mathrm{E}$ improves arterial stiffness and endothelial function in essential hypertensive patients. Am J Hypertens 2007;20:392-7.

[98] Zureik M, Galan P, Bertrais S, Mennen L, Czernichow S, Blacher J, et al. Effects of long-term daily low-dose supplementation with antioxidant vitamins and minerals on structure and function of large arteries. Arterioscler Thromb Vasc Biol 2004;24:1485-91.

[99] Eskurza I, Monahan KD, Robinson JA, Seals DR. Ascorbic acid does not affect large elastic artery compliance or central blood pressure in young and older men. Am J Physiol Heart Circ Physiol 2004;286:H1528-H34.
[100] Woods MN, Wanke CA, Ling PR, Hendricks KM, Tang AM, Knox TA, et al. Effect of a dietary intervention and n-3 fatty acid supplementation on measures of serum lipid and insulin sensitivity in persons with HIV. Am J Clin Nutr 2009;90:1566-78.

[101] Khalil ML. Biological activity of bee propolis in health and disease. Asian Pac J Cancer Prev 2006;7:22-31.

[102] Yagi K, Kim S, Wanibuchi H, Yamashita T, Yamamura Y, Iwao H. Characteristics of diabetes, blood pressure, and cardiac and renal complications in Otsuka Long-Evans Tokushima Fatty rats. Hypertension 1997;29:728-35.

[103] Kawano K, Hirashima T, Mori S, Natori T. OLETF (Otsuka Long-Evans Tokushima Fatty) rat: a new NIDDM rat strain. Diabetes Res Clin Pract 1994;24:S317-S20.

[104] Fukuda T, Fukui M, Tanaka M, Senmaru T, Iwase H, Yamazaki M, et al. Effect of Brazilian green propolis in patients with type 2 diabetes: a double-blind randomized placebo-controlled study. Biomed Rep 2015;3:355-60.

[105] Pajor AM. Sodium-coupled dicarboxylate and citrate transporters from the SLC13 family. Pflügers Arch 2014;466: 119-30.

[106] Hosogi S, Ohsawa M, Kato I, Kuwahara A, Inui T, Inui A, et al. Improvement of diabetes mellitus symptoms by intake of Ninjin'yoeito. Front Nutr 2018;5:112. 